\title{
Mineral Profiling of Chickpea Wilt against Fusarium oxysporum f.sp. ciceris
}

\author{
Hafiz Tassawar Abbas" ${ }^{*}$, Tamoor Khan', Ghulam Khaliq², Muhammad Aqeel Sarwar ${ }^{3}$, Muhammad \\ Rashid ${ }^{4}$, Intazar Ali ${ }^{5}$, Muhammad Abuzar Jaffar ${ }^{2}$, Ghulam Ali Bugti ${ }^{6}$ and Muhammad Waseem ${ }^{4}$
}

${ }^{1}$ Department of Plant Pathology, Faculty of Agriculture, Lasbela University of Agriculture, Water and Marine Sciences, Uthal, District Lasbela, Balochistan, Pakistan; ${ }^{2}$ Faculty of Agriculture, Lasbela University of Agriculture, Water and Marine Sciences, Uthal, District Lasbela, Balochistan, Pakistan; ${ }^{3}$ Crop Sciences Institute, National Agricultural Research Centre Islamabad, Pakistan; ${ }^{4}$ Department of Agronomy, Faculty of Agriculture, Lasbela University of Agriculture, Water and Marine Sciences, Uthal, District Lasbela, Balochistan, Pakistan; ${ }^{5}$ Department of Entomology, University College of Agriculture and Environmental Sciences, The Islamia University of Bahawalpur, Pakistan; ${ }^{6}$ Department of Entomology, Faculty of Agriculture, Lasbela University of Agriculture, Water and Marine Sciences, Uthal, District Lasbela, Balochistan, Pakistan.

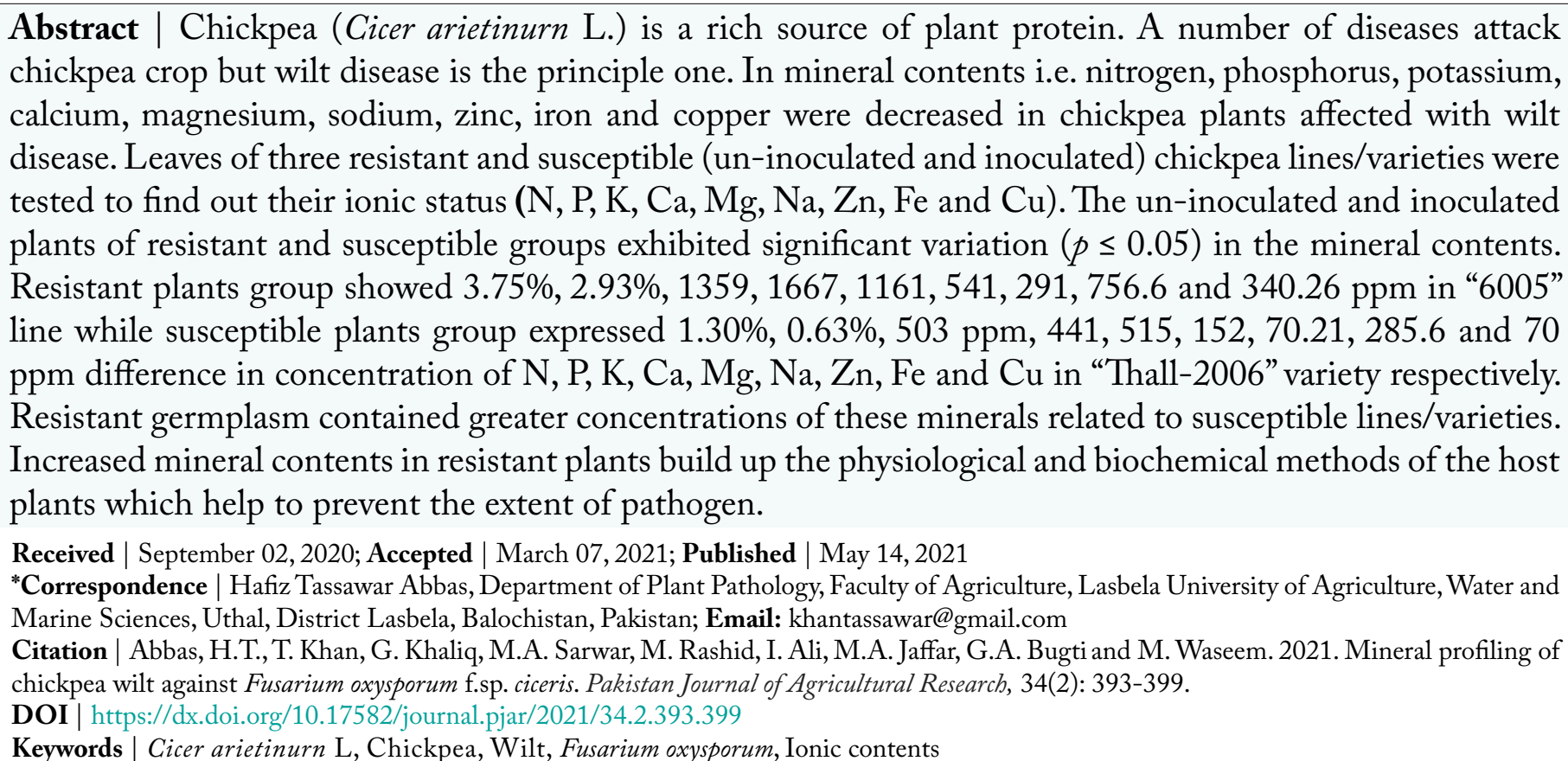

\section{Introduction}

$\mathrm{C}$ hickpea (Cicer arietinurn L.) is cheap and a rich source of plant protein and considered alternate to animal protein. Chickpea is grown under irrigated and rainfed conditions. In Pakistan it can be cultivated in September and November. $2^{\text {nd }}$ week of October is the appropriate time for the cultivation of chickpea crop in Punjab followed by Kyber Pakhtunkhwa and
Sindh FAO (2009). Pakistan is the major producer among chickpea producing countries in the world. Chickpea grain contains protein contents 25.3-28.9\%, oil 3\%, carbohydrate 38-59\%, $0.3 \%$ phosphorus, and ash fiber $4.8-5.5 \%$ with little kind of ionic contents (Hulse, 1991; Amjad et al., 2006; Daur et al., 2008). Various factors responsible in low chickpea grain yields in Pakistan. However, the biological limitations are the most significant factor of low yield in chickpea. June 2021 | Volume 34 | Issue 2 | Page 393 
Among these limitations flagging and wilting are responsible for chickpea wilt incited by $F$. oxysporum f.sp. ciceris and subsequently loss in yield of the sick plants (Haqqani et al., 2000). Wilt infected seedlings dried quickly, distorted and fall on the ground. Early seedlings mortality (within 25 to 30 days after sowing) and death of adult plants occur due to development of this disease (Haware et al., 1978). Chickpea wilt is the most destructive disease causing $10-50 \%$ crop loss annually in Pakistan (Khan et al., 2002).

Disease severity is affected by nutrition which effects totally intermingling constituents. Pathogen and plant were also affected due to nutrients. Contribution of nutrients is vigorous and necessary minerals impact plant diseases interaction. However, a plant is infected which decreases movement, absorption and consumption of mineral nutrients due to a pathogen. Some microorganisms limit the mobility of nutrients in infected tissues or in soil and restrict uptake of nutrients which prompt toxicity or deficiency of minerals. Some others use minerals like N, P, K, Ca, $\mathrm{Mg}, \mathrm{Zn}, \mathrm{Cu}$ and $\mathrm{Fe}$ in their body, thus reducing their accessibility to the plant and thereby increasing the plant's susceptibility to disease infection (Timothy and Arnold, 2010; Sahi et al., 2010). A dire need is felt to strengthen the host plant health to manage with the alarming issue of Fusarium wilt of chickpea. So, keeping in view the importance of chickpea wilt disease, the recent study was planned to determine the relationship between ionic contents $(\mathrm{N}, \mathrm{P}, \mathrm{K}$, $\mathrm{Ca}, \mathrm{Mg}, \mathrm{Na}, \mathrm{Zn}, \mathrm{Fe}$ and $\mathrm{Cu}$ ) of diseased and healthy plants which may help in understanding disease development machanism.

\section{Materials and Methods}

\section{Collection of diseased samples}

Diseased samples were collected from the different farmer's fields of Cholistan desert in Bahawalpur region. These samples were brought to laboratory of Cholistan Institute of Desert studies (CIDS), The Islamia University of Bahawalpur, Pakistan for further study.

Isolation, identification and mass culturing of Fusarium oxysporum f.sp. ciceris

Chickpea infected roots were cut into 5-8 $\mathrm{mm}$ pieces, washed with tap water and surface sterilized by $1 \%$ $(\mathrm{NaOCl})$ sodium hypochlorite for one minute. These pieces were given three washings in disinfected water and placed on sterilized filter paper sheet for drying. These sterilized pieces were transferred in Petri plates contained autoclaved potato dextrose agar and incubated at $26 \pm 2{ }^{\circ} \mathrm{C}$ for 7 days. The colony of Fusarium oxysporum was observed and identified with the help of relevance literature. Pure culture of Fusarium oxysporurm was kept in autoclaved test tubes in the refrigerator at $4{ }^{\circ} \mathrm{C}$ for further investigations.

\section{Determination of ionic status in chickpea cultivars}

Seeds of all six advanced lines/variety $(6005,6010$, 6015, 7021, 8020 and Thall-2006) were collected from NARC, Islamabad and Ayub Agricultural Research Institute (AARI) Faisalabad for determination of biochemical changes due to attack of wilt disease in chickpea leaves. Seeds of all advanced lines/variety were grown into earthen pots $\left(20 \times 15 \mathrm{~cm}^{2}\right)$ contained $1 \mathrm{Kg}$ autoclaved soil in each pot and inoculated with a $1 \times 10^{4}$ spores $\mathrm{L}^{-1}$ suspension of Fusarium oxysporurm through Haemocytometer at initial flowering stage (Landa et al., 2001). Then pots were kept on glass house bench at $26 \pm 2{ }^{\circ} \mathrm{C}$ under CRD. Each treatment contained three replications. All recommended agronomic operations were used. Plant samples which were harvested composed of two groups i.e. uninoculated and inoculated; each group was consisted of two types (Susceptible and Resistant). Resistant group contained three advanced lines 6005, 6010, and 6015 while susceptible group contained three lines/ variety 7021, 8020 and Thall-2006.

To remove dust leaves of both resistant and susceptible chickpea cultivars washed with $0.2 \%$ detergent, to eliminate impurities and again washed in $0.8 \%$ $\mathrm{HCl}$. Dried samples were kept in paper bags and dehydrated for three days at $70{ }^{\circ} \mathrm{C}$ in oven. The dried grounded samples $(100 \mathrm{mg})$ were boiled in $10 \mathrm{ml}$ of 1.4 $\mathrm{N} \mathrm{HNO}_{3}$ on hotplate (TH-550; Advantec, Tokyo, Japan) for half an hour at $100{ }^{\circ} \mathrm{C}$. The mixture was diluted 250 times with distilled water after cooling and then it was investigated for the finding of N, P, $\mathrm{K}, \mathrm{Ca}, \mathrm{Mg}, \mathrm{Na}, \mathrm{Zn}, \mathrm{Fe}$ and $\mathrm{Cu}$ following Bhargava and Raghurpathi (1995) procedure. Nitrogen and phosphorous were determined on percent basis, while other elements were noted as parts per million (ppm).

\section{Statistical analysis}

The experiment was done under CRD. Collected data was interoperated by statistical analysis. All these data recorded from the experiment were analyzed and means using least significant difference LSD $(\mathrm{P} \leq$ 
0.05) and in SAS/STAT statistical software (Steel et al., 1997; SAS Institute, 1990).

\section{Results and Discussion}

\section{Determination of $N, P, K, C a$ and $M g$ from inoculated and un-inoculated chickpea plants}

The samples of inoculated and un-inoculated plants from both resistant and susceptible plants were evaluated for $\mathrm{N}, \mathrm{P}, \mathrm{K}, \mathrm{Ca}$, and $\mathrm{Mg}$. The un-inoculated and inoculated plants of resistant and susceptible groups were also significantly different from one another $(p \leq 0.05)$. Nitrogen content was higher in un-inoculated as well as in inoculated plants of resistant lines compared with that of susceptible lines/ variety. The maximum quantity of $\mathrm{N}$ was showed by "6005" line at $3.75 \%$ in un-inoculated plants and the minimum by "Thall-2006" at $1.30 \%$ in inoculated plants (Table 1).

Regarding phosphorus contents, significant variation was observed among un-inoculated and inoculated plants during disease stress at $(p \leq 0.05)$. P contents were higher in un-inoculated as well as inoculated plants of resistant ones as compared with that of susceptible lines/variety i.e. 6005 line and Thall-2006 showed maximum and minimum concentration of $\mathrm{P}$ to the sort of $2.93 \%$ in un-inoculated plants and
$0.63 \%$ in inoculated plants correspondingly as shown in Table 1.

The potassium content in un-inoculated as well as inoculated plants of susceptible group was lower than that of resistant group. There was a highly significant decrease in $\mathrm{K}$ content in the plants of susceptible group than in resistant as an outcome of inoculation $(p \leq 0.05)$. The minimum amount of $\mathrm{K}$ was detected by "Thall-2006" at $503 \mathrm{ppm}$ in inoculated plants and the maximum by "6005" at $1359 \mathrm{ppm}$ in un-inoculated plants individually as expressed in (Table 1 ).

Statistically significant difference was recorded regarding $\mathrm{Ca}$ in un-inoculated and inoculated plants of resistant and susceptible groups $(p \leq 0.05)$. $\mathrm{Ca}$ concentration of $1667 \mathrm{ppm}$ was presented by 6005 in un-inoculated plants (Resistant group), while 441ppm concentration in inoculated plants was expressed by Thall-2006 (Susceptible group) separately as presented in Table 1.

$\mathrm{Mg}$ contents were found having significant variation in resistant and susceptible groups. Line 6005 (Resistant group) and Thall-2006 (Susceptible group) exhibited $1161 \mathrm{ppm}$ (maximum) in un-inoculated plants and $515 \mathrm{ppm}$ (minimum) concentration in inoculated plants separately (Table 1).

Table 1: Nitrogen, phosphorus, potassium, calcium, magnesium, sodium, zinc, iron and copper contents for the reaction groups and lines/cultivar of chickpea.

\begin{tabular}{|c|c|c|c|c|c|c|c|c|c|c|c|c|}
\hline \multicolumn{13}{|c|}{ Nitrogen (\%) } \\
\hline \multirow{2}{*}{$\begin{array}{l}\text { Lines/cultivar } \\
\text { Type }\end{array}$} & \multicolumn{2}{|c|}{6005} & \multicolumn{2}{|c|}{6010} & \multicolumn{2}{|c|}{6015} & \multicolumn{2}{|c|}{7021} & \multicolumn{2}{|c|}{8020} & \multicolumn{2}{|c|}{ Thall-2006 } \\
\hline & \multicolumn{6}{|c|}{ Resistant group } & \multicolumn{6}{|c|}{ Susceptible group } \\
\hline \multirow{2}{*}{ Group } & Unin. & Inoc. & Unin. & Inoc. & Unin. & Inoc. & Unin. & Inoc. & Unin. & Inoc. & Unin. & Inoc. \\
\hline & $3.75 \mathrm{a}$ & $2.7 \mathrm{c}$ & $3.11 \mathrm{~b}$ & $2.24 \mathrm{~d}$ & $2.94 \mathrm{~b}$ & $1.96 \mathrm{e}$ & $2.79 \mathrm{a}$ & $2.37 \mathrm{~b}$ & $2.14 \mathrm{c}$ & $1.87 \mathrm{~d}$ & $1.57 \mathrm{e}$ & $1.30 \mathrm{f}$ \\
\hline \multicolumn{13}{|l|}{ Phosphorus (\%) } \\
\hline & $2.93 \mathrm{a}$ & $2.11 \mathrm{c}$ & $2.48 \mathrm{~b}$ & $1.82 \mathrm{~d}$ & $2.04 \mathrm{c}$ & $1.50 \mathrm{e}$ & $1.59 \mathrm{a}$ & $1.09 b$ & $1.07 \mathrm{~b}$ & $0.85 \mathrm{c}$ & $0.81 \mathrm{c}$ & $0.63 \mathrm{~d}$ \\
\hline \multicolumn{13}{|c|}{ Potassium (ppm) } \\
\hline & $1359 a$ & $947 \mathrm{c}$ & $1031 b$ & $887 \mathrm{e}$ & $917 \mathrm{~d}$ & $635 \mathrm{f}$ & $823 \mathrm{a}$ & $624 d$ & $700 \mathrm{~b}$ & $529 e$ & $648 c$ & $503 f$ \\
\hline \multicolumn{13}{|l|}{ Calcium (ppm) } \\
\hline & $1667 \mathrm{a}$ & $1243 d$ & $1421 b$ & $1122.33 \mathrm{e}$ & $1319 \mathrm{c}$ & $1056 f$ & $1167 \mathrm{a}$ & $771 d$ & $960 \mathrm{~b}$ & $534 \mathrm{e}$ & $845 c$ & $441 f$ \\
\hline \multicolumn{13}{|c|}{ Magnesium (ppm) } \\
\hline & $1161 \mathrm{a}$ & $985 \mathrm{~d}$ & $1112 b$ & $927 \mathrm{e}$ & $1043 c$ & $874 f$ & $981 \mathrm{a}$ & $829 c$ & $911 b$ & $782 \mathrm{~d}$ & $734 \mathrm{e}$ & $515 \mathrm{f}$ \\
\hline \multicolumn{13}{|l|}{ Sodium (ppm) } \\
\hline & $541 \mathrm{a}$ & $477.23 b$ & $491 b$ & $419.4 \mathrm{~d}$ & $446 c$ & $374 \mathrm{e}$ & $386 a$ & $318 b$ & $321.53 b$ & $265 c$ & $241.8 \mathrm{~d}$ & $152 \mathrm{e}$ \\
\hline \multicolumn{13}{|l|}{ Zinc (ppm) } \\
\hline & $291 \mathrm{a}$ & $243.11 b$ & $236 \mathrm{~b}$ & $170.32 d$ & $202 c$ & $144.15 \mathrm{e}$ & $175 \mathrm{a}$ & $123 c$ & $154 \mathrm{~b}$ & $101 d$ & $125 \mathrm{c}$ & $70.27 \mathrm{e}$ \\
\hline \multicolumn{13}{|l|}{ Iron (ppm) } \\
\hline & $756.6 \mathrm{a}$ & $624 d$ & $714.8 \mathrm{~b}$ & $567.2 \mathrm{e}$ & $659 c$ & $480.9 \mathrm{f}$ & $601 \mathrm{a}$ & $559.12 \mathrm{~b}$ & $486 c$ & $427 \mathrm{~d}$ & $363 e$ & $285.6 \mathrm{f}$ \\
\hline \multicolumn{13}{|l|}{ Copper (ppm) } \\
\hline & $340.26 \mathrm{a}$ & $284 c$ & $305.63 \mathrm{~b}$ & $235 \mathrm{~d}$ & $270 c$ & $187.23 \mathrm{e}$ & $207 \mathrm{a}$ & $142 c$ & $176 b$ & $114 \mathrm{~d}$ & $102 \mathrm{e}$ & $70 f$ \\
\hline
\end{tabular}

June 2021 | Volume 34 | Issue 2 | Page 395 
Determination of $\mathrm{Na}, \mathrm{Zn}, \mathrm{Fe}$ and $\mathrm{Cu}$ from inoculated and un-inoculated chickpea plants

The inoculated plants of resistant and susceptible groups differed significantly $(p \leq 0.05)$ from uninoculated plants of their respective groups. $\mathrm{Na}$ content was significantly higher in resistant group (both in un-inoculated and inoculated plants) than in susceptible group. $\mathrm{Na}$ contents 318,265 and $152 \mathrm{ppm}$ concentrations were observed minimum in inoculated plants of susceptible lines/variety 7021, 8020 and Thall-2006 while 541, 491and 446 ppm were shown maximum by un-inoculated plants of 6005,6010 and 6015 (Resistant group) separately as shown in Table 1.

Un-inoculated and inoculated plants of resistant and susceptible groups exhibited significant variation in $\mathrm{Zn}$ at $(p \leq 0.05)$. $\mathrm{Zn}$ concentrations of 291,236 and $202 \mathrm{ppm}$ (maximum) were found for 6005, 6010 and 6015 in un-inoculated plants (Resistant group), while 123, 101 and $70.27 \mathrm{ppm}$ concentrations in inoculated plants were expressed by the susceptible group 7021, 8020, and Thall-2006, respectively (Table 1).

Significant variation was achieved by resistant and susceptible cultivars in Fe concentrations. Lines 6005 (756.6 ppm), 6010 (714.8 ppm) and 6015 (659 ppm) gave maximum concentrations in un-inoculated plants (Resistant group), while 7021 (559.12 ppm), 8020 (427 ppm), and Thall-2006 (285.6 ppm) at ( $p$ $\leq 0.05)$ gave minimum concentrations in inoculated plants of susceptible group correspondingly as expressed in Table 1.

Significantly $\mathrm{Cu}$ differed in both un-inoculated and in inoculated plants of resistant and susceptible group under disease stress conditions. Resistant group like 6005 (340.26 ppm), 6010 (365.63 ppm) and 6015 $(270 \mathrm{ppm})$ while susceptible group i.e. 7021 (142 ppm), 8020 (114 ppm) and Thall-2006 (70 ppm) expressed their large and least concentrations at $(p \leq$ 0.05 ) individually (Table 1 ).

Excessive/deficiency amount of nutrients causes different diseases in plants which are affected by amount of elements, type of disease, type of element and environmental factors which effect on disease appearance. Macro and micro nutrients are essential for the growth of plants and completion of their life cycle. Different types of nutrients may affect the resistance status of the host as well as virulence of the pathogen. Plants attaining well balanced nutrition, with all essential elements easily available in proper amount undergo a smaller amount of disease and get protection from outcomes of new infection and exhibited distinct growth, and yield (Mishra et al., 2005). In recent study a remarkable effect of chickpea wilt disease was observed on the nourishing status of plants.

Nitrogen is an important constituent of many vital biochemicals such as nucleic acids, proteins, coenzymes and amino acids in plant tissues (Lakitan, 2007). Plants need huge amount of nitrogen for normal growth, hence they respond quickly to application of nitrogen (Spann and Schumann, 2010). Some diseases produce due to nitrogen excess in soil while its deficit also favors some disorders in plants (Dordas, 2008; Waller et al., 2007; Hoffland et al., 2000). The inoculated chickpea cultivars contained less nitrogen in susceptible types while the un-inoculated of resistant chickpea lines carried more nitrogen contents. These results are in agreement with the outcomes of Jadon and Shah (2012).

Phosphorus is second essential element for the development of DNA, RNA, phospholipids, ATP, $\mathrm{NADP}$ and NAD and some compounds of great energy used by the plants (Huber and Graham, 1999). Phosphorus nutrition improves crop vigour and may decrease severity of diseases through new growth (Buresh,1997; Smyth and Cassell, 1995).Phosphorous enhanced root development may help the plant to escape fungal pathogens (Prabhu et al., 2007). The un-inoculated and inoculated plants in susceptible group as well as in resistant one differs remarkably with regard to phosphorous concentrations. These findings are also in line with the results of Jadon and Shah (2012).

Potassium has a key role in metabolism of carbohydrates, stomatal opening and photosynthesis (Huber and Graham, 1999; Rice, 2007). In present study, decrease in $\mathrm{K}$ amount was noted in resistant group but more pronounced reduction in susceptible group due to chickpea wilt disease. These results are supported by the results of Mishra et al.(2005), Dordas (2008), Jadon and Shah (2012) who described similar pattern $\mathrm{K}$ contents of diseased and healthy plants.

Calcium is primarily significant part of plant cell wall. It helps in root development, stimulation of leaf, microbial activity and uptake of nutrients. It 
produces resistance in host plant because it checks the penetration of pathogens (Devlin and Withman, 1983; Mishra et al., 2005). Significant decrease in Ca contents was found both in susceptible and resistant cultivars which pronounced disease (Marschner, 1995; Mishra et al., 2005). Similar work was reported by Dordas (2008) and Amusa et al. (2005).

Magnesium plays a vital role in photosynthesis, chlorophyll contents and carbohydrate metabolism (Spann and Schumann, 2010). Mg is a dynamic element of structural tissues and plays an important role in altered physiological and biochemical processes. In present study increase in magnesium concentrations was observed in resistant cultivars as compared to susceptible lines/variety. These findings are in agreement with the results of Jadon and Shah (2012), Sawant and Gawai (2011) and Amusa et al. (2005).

Sodium $(\mathrm{Na})$ is utilized by plants as sodium ions which significantly differed in the existing study. The un-inoculated and inoculated of resistant group contained more sodium as related to susceptible group. Our outcomes are in agreement with the results of Jadon and Shah (2012).

Zinc shows resistance against many diseases but its mechanism in disease resistance is indistinct. It acts as co-factor for various enzymes (Rice, 2007; Cakmak, 2000). A significant dissimilarity in $Z$ n contents was noticed in chickpea lines while low contents of $\mathrm{Zn}$ was found in inoculated chickpea lines/varieties as compared to un-inoculated plants. Our results are supported by Reddy and Khare (1984) and Sahi et al. (1999).

Iron is the primary constituent of chlorophyll and has significant role in metabolism and nucleic acid. Chlorophyll contents of plants reduce due to its deficiency (Imran and Gurmani, 2011). In current study it was found that $\mathrm{Fe}$ contents were reduced due to fungal attack. It may be due to the fact that plant pathogens mostly have greater requisite of $\mathrm{Fe}$ and act as virulence factor during the disease development with the help of Fe activate enzymes (Graham and Webb, 1991; Dordas, 2008).

Copper is a significant constituent of lignin and have a vital role in carbohydrate metabolism and protein. It acts as catalyst in altered metabolic activities of the plant (Imran and Gurmani, 2011). Significant variation was found in $\mathrm{Cu}$ concentration of uninoculated and inoculated plants of both groups i.e. resistant and susceptible upon infection with Fusarium oxysporum f.sp ciciris (Foc). Conclusion of the current study is agreed by the work of Mata et al. (2001). Cu has direct lethal effects on plant pathogens and its scarcity declines lignification in the xylem (Evans et al., 2007).

\section{Conclusions and Recommendations}

Mineral contents i.e. Nitrogen, Phosphorus, Potassium, Calcium, Magnesium, Sodium, Zinc, Iron and Copper were decreased in chickpea plants affected with wilt disease. Appropriate utilization of these nutrients helps in the host plants in strengthening of its physical and biochemical processes, which finally help in increasing the resistance against wilt disease of chickpea.

\section{Acknowledgments}

Authors are extremely grateful to Higher Education Commission (HEC) Pakistan for funding this study.

\section{Novelty Statement}

In the recent study increased mineral contents in resistant plants build up the physiological and biochemical methods of the host plants which help to prevent the extent of pathogen.

\section{Author's Contribution}

Hafiz Tassawar Abbas: Conducted the research and wrote the manuscript.

Tamoor Khan, Ghulam Khaliq and Muhammad Aqeel Sarwar: Designed the experiment and gave valuable suggestions on data analysis.

Muhammad Rashid, Ghulam Ali Bugti and Intazar

Ali: Helped in revision of manuscript.

Muhammad Abuzar Jaffar and Muhammad Waseem: Contributed in final proof reading of manuscript.

Conflict of interest

The authors have declared no conflict of interest.

\section{References}

Amjad,I.,I.A.Khalil,A.Nadia and K.S.Muhammad. 
2006. Nutritional quality of important food legumes. Food Chem., 97(2): 331-335. https:// doi.org/10.1016/j.foodchem.2005.05.011

Amusa, N.A., A.O. Ashaye, M.O. Oladapo and M.O. Oni. 2005. Guava fruit anthracnose and the effects on its nutritional and market values in Ibadan, Nigeria. World J. Agric. Sci., 1(2): 169-172.

Bhargava, B.S. and H.B. Raghurpathi. 1995. Analysis of plant material for macro and micronutrients. In: Methods ofgrowth of Rbizoctonia infected wheat seedlings. Plant Soil. 209: 157-166.

Buresh, R.J., P.C. Smithson and D.T. Hellums. 1997. Building Soil P Capital in Africa. In Replenishing Soil Fertility in Africa, edited by R.J. Buresh, P.A. Sanchez and F.G. Calhoun. Madison, Wisconsin: Soil Science Society of America.pp.111-149. https://doi.org/10.2136/ sssaspecpub51.c6

Cakmak, I.M., 2000. Possible roles of zinc in protecting plant cells from damage by reactive oxygen species. New Phytol., 146: 185-205. https://doi.org/10.1046/j.14698137.2000.00630.x

Daur, I., I.A. Khan and M. Jahangir. 2008. Nutritional quality of roasted and pressurecooked chickpea compared to raw (Cicer arietinum L.) seeds. Sarhad J. Agric., 24(1): 117-122.

Devlin, R.M. and F.H. Witham. 1983. Plant Physiology. Wards worth Pub. Co., California, USA.pp. 577.

Dordas, C., 2008. Role of nutrients in controlling plant diseases in sustainable agriculture, A review, J. Agron. Sustain. Dev., 28: 33-46. https://doi.org/10.1051/agro:2007051

Evans, I., E. Solberg, and D.M. Huber. 2007. Copper and plant disease. In mineral nutrition and plant disease, edited by L.E. Datnoff, Wade H. Elmer and D.M. Huber, 177-88. St. Paul, Minn: Am. Phytopathol. Soc.,

Food and Agriculture Organization of the United Nations. 2009. Production Yearbook. Rome, Italy.

Graham,R.D.and M.J.Webb.1991.Micronutrients and disease resistance and tolerance in plants. In: J.J. Mortvedt, F.R Cox, L.M. Shuman and R.M. Welch (eds.), Micronutrients in agriculture, $2^{\text {nd }}$ Ed., SSSA, Madison, WI. pp. 329-370. https:// doi.org/10.2136/sssabookser4.2ed.c10
Haqqani, A.M., Zahid M.A. and M.R. Malik. 2000. Legumes in Pakistan. In: Legumes in rice cropping system of the Indo-Gangetic Planesconstraints and opportunities ICRISAT. India. pp. 98-128.

Haware, M.P., Y.L. Nene and R. Rajeswari. 1978. Eradication of Fusarium oxysporum f. sp. ciceris transmitted in chickpea seed. Phytopathology, 68: 1364-1368. https://doi.org/10.1094/ Phyto-68-1364

Hoffland, E., M.J. Jegger and M.L. van Beusichem. 2000. Effect of nitrogen supply rate on disease resistance in tomato depends on the pathogen. Plant Soil, 218: 239-247. https://doi. org/10.1023/A:1014960507981

Huber, D.M. and R.D. Graham. 1999. The role of nutrition in crop resistance and tolerance to disease. In: Rengel, Z., (Ed.), Mineral Nutrition of Crops Fundamental Mechanisms and Implications. Food Product Press, New York, pp. 205-226.

Hulse, J.H., 1991. Nature, composition and utilization of grain legumes. In: Uses of tropical Legumes: Proceedings of a Consultants' Meeting, 27-30 March 1989, ICRISAT Center. ICRISAT, Patancheru, A.P. 502 324, India. pp. 11-27.

Imran, M. and Z.A. Gurmani. 2011. Role of macro and micro nutrients in the plant growth and development. Sci. Tec. Dev., 30: 36-40.

Jadon, K.S. and R. Shah. 2012. Effect of Drechslera bicolor Infection on physiology of Bell Pepper. J. Plant Pathol. Microbiol., 3(4): 126-129.

Khan, I.A., S.S. Alam, A. Haq and A. Jabbar. 2002. Selection for resistant to wilt in relation with phenols in chickpea. Int. Chickpea Pigeonpea Newsl., 9: 19-20.

Lakitan,B.,2007. Fundamentals of plant physiology. Raja Grafindo Persada. Jakarta. Indonesia.

Landa, B.B., J.A. Navas-Cortés, A. Hervás and R.M. Jiménez-Díaz. 2001. Influence of temperature and inoculum density of Fusarium oxysporum f. sp. ciceris on suppression of Fusarium wilt of chickpea by rhizosphere bacteria. Phytopathology, 91: 807-816. https:// doi.org/10.1094/PHYTO.2001.91.8.807

Marschner, H., 1995. Mineral Nutrition of Higher Plants, $2^{\text {nd }}$ Ed. Academic, London, pp. 889.

Meta, C.G., L. Lammatina and R.O. Cassia. 2001. Involvement of iron and ferritin Phytophthora infestans interaction. Eur. 
J. Pl. Pathol., 107: 557-562. https://doi. org/10.1023/A:1011228317709

Mishra, A., J.S. Wasir and R.M. Pandey. 2005. An evaluation of candidate definitions of the metabolic syndrome in adult Asian Indians. Diabetes Care, 28: 398-403. https://doi. org/10.2337/diacare.28.2.398

Prabhu, A.S., N.K. Fageria, D.M. Huber, and F.A. Rodrigues. 2007. Potassium and Plant Disease. In mineral nutrition and plant disease, edited by L.E. Datnoff, Wade, H. Elmer and D.M.Huber, 57-78. St. Paul. Minn: Am. Phytopathol. Soc.,

Reddy, R.R. and M.N., Khare. 1984. Furthure studies on factors influencing the mechanism of resistance in lentil (Lens culinaris $\mathrm{M}$.) to rust (Uromyces fabae (Pers.) de Bary). LENS Newsl., 11(2): 29-32.

Rice, R.W., 2007.The physiological role of minerals in plants. In mineral nutrition and plant disease, edited by L.E. Datnoff, Wade H. Elmer and D.M. Huber, St. Paul, Minn: Am. Phytopathol. Soc., pp. 9-30.

Sahi, S.T., 1999. Determination of some Morphological and Biochemical characters of lentil (Lens culinaris Medik.) for resistance against Ascochyta blight. pp. 133.

Sahi, S.T., M.U. Ghazanfar, M. Afzal, W. Wakil and A. Habib. 2010. Influence of inoculation with aschochyta lentis on mineral contents $(\mathrm{Na}, \mathrm{Ca}, \mathrm{Mg}, \mathrm{Zn}, \mathrm{Cu}$ and $\mathrm{Fe}$ ) of susceptible and resistant lines of lentil (Lens culinaris Medik.). Pak. J. Bot., 42(1): 375-382.

SAS Institute. 1990. SAS/STAT User's Guide. $6^{\text {th }}$ ed. SAS Institute, Cary, NC, USA.

Sawant, S.G. and D.U. Gawai. 2011. Effect of fungal infection on nutritional value of papaya fruits. Curr. Bot., 2: 43-44.

Smyth, T.J., and D.K. Cassell. 1995. Synthesis of long-term soil management research on ultisols and oxisols in the amazon. In soil management: Experimental basis for sustainability and environmental quality, edited by R. Lal and B. A. Stewart. Boca Raton: Lewis Publishers.

Spann, T.M. and A.W., Schumann. 2010. Mineral nutrition contributes to plant disease and pest resistance. Series No. HS1181, Horticultural sciences department, UF/IFAS Extension, University of Florida, Gainesville, FL.

Steel, R.G.D., J.H. Torrie and D.A. Dickey. 1997. Principles and procedures of statistics, a biometrical approach. 3. Boston: McGraw-Hill.

Timothy M.S. and W.S. Arnold. 2010. Mineral nutrition contributes to plant disease and pest resistant, Univ. of Florida, IFAS Extention. http://edis.ifas.ufl.edu.

Waller, J.M., M. Bigger and R.J. Hillocks. 2007. Coffee pests, diseases and their management. Cambridge, MA: CABI Publ. https://doi. org/10.1079/9781845931292.0000 